\title{
Singlet oxygen luminescence as an in vivo photodynamic therapy dose metric: validation in normal mouse skin with topical amino-levulinic acid
}

\author{
MJ Niedre ${ }^{1,2}$, CS Yu ${ }^{1,2}$, MS Patterson ${ }^{3,4}$ and BC Wilson*,1,2 \\ 'Department of Medical Biophysics, Ontario Cancer Institute/University Health Network Ontario, Canada; '2University of Toronto, Toronto, Ontario, \\ Canada; ${ }^{3}$ Juravinski Cancer Center,Hamilton, Ontario, Canada; ${ }^{4}$ McMaster University, Hamilton, Ontario, Canada
}

Although singlet oxygen $\left({ }^{\prime} \mathrm{O}_{2}\right)$ has long been proposed as the primary reactive oxygen species in photodynamic therapy (PDT), it has only recently been possible to detect it in biological systems by its luminescence at $1270 \mathrm{~nm}$. Having previously demonstrated this in vitro and in vivo, we showed that cell survival was strongly correlated to the ${ }^{\prime} \mathrm{O}_{2}$ luminescence in cell suspensions over a wide range of treatment parameters. Here, we extend this to test the hypothesis that the photobiological response in vivo is also correlated with ${ }^{\prime} \mathrm{O}_{2}$ generation, independent of individual treatment parameters. The normal skin of SKHI-HR hairless mice was sensitised with $20 \%$ amino-levulinic acid-induced protoporophyrin IX and exposed to $5,11,22$ or $50 \mathrm{~J} \mathrm{~cm}{ }^{-2}$ of pulsed $523 \mathrm{~nm}$ light at $50 \mathrm{~mW} \mathrm{~cm}^{-2}$, or to $50 \mathrm{~cm}^{-2}$ at 15 or $150 \mathrm{~mW} \mathrm{~cm}^{-2}$. ${ }^{1} \mathrm{O}_{2}$ luminescence was measured during treatment and the photodynamic response of the skin was scored daily for 2 weeks after treatment. As observed by other authors, a strong irradiance dependence of the PDT effect was observed. However, in all cases the responses increased with the ${ }^{\prime} \mathrm{O}_{2}$ luminescence, independent of the irradiance, demonstrating for the first time in vivo an unequivocal mechanistic link between ${ }^{\prime} \mathrm{O}_{2}$ generation and photobiological response.

British Journal of Cancer (2005) 92, 298-304. doi: I 0.1038/sj.bjc.660233 I www.bjcancer.com

Published online 18 January 2005

(c) 2005 Cancer Research UK

Keywords: photodynamic therapy; singlet oxygen; luminescence; dosimetry

Photodynamic therapy (PDT) is an emerging therapy for the treatment of solid tumours and some nonmalignant conditions (Dougherty et al, 1998; Stewart et al, 1998). The therapy involves the activation of light-sensitive drugs with a laser or other light source to generate reactive oxygen species (ROS). For most clinically used photosensitisers, the most important ROS is believed to be singlet oxygen $\left({ }^{1} \mathrm{O}_{2}\left({ }^{1} \Delta_{\mathrm{g}}\right)\right.$ ) (Weishaupt et al, 1976). The action of ${ }^{1} \mathrm{O}_{2}$ results in modification or destruction of the target tissue and subsequent clinical effects (Schweitzer and Schmidt, 2003).

Since PDT involves three interdependent and dynamic treatment factors (i.e. light, photosensitiser and oxygen), complete and accurate dosimetry is a difficult problem and is the focus of ongoing research by several groups. Several techniques have been proposed (Wilson et al, 1997a), such as 'explicit dosimetry', in which the quantities of light, drug and oxygen are continuously monitored during treatment. Alternatively, 'implicit dosimetry' utilises a surrogate for biological damage, such as the photodegradation of the photosensitiser (fluorescence) during treatment to predict treatment outcome (Wilson et al, 1997a; Dysart et al, 2002).

*Correspondence: BC Wilson, Department of Medical Biophysics, Ontario Cancer Institute/University Health Network, 610 University Avenue, Toronto, ON M5G 2M9, Canada;

E-mail:wilson@uhnres.utoronto.ca

Received 28 June 2004; revised 25 October 2004; accepted 25 October 2004; published online 18 January 2005
The focus of the present work is 'direct dosimetry', which entails direct measurement of ${ }^{1} \mathrm{O}_{2}$ during treatment.

In $\mathrm{PDT},{ }^{1} \mathrm{O}_{2}$ is generated by the following type-II pathway (Patterson et al, 1990):

$$
\begin{aligned}
& \mathrm{S}_{0}+h v \rightarrow \mathrm{S}_{1} \\
& \mathrm{~S}_{1} \rightarrow \mathrm{T}_{1} \\
& \mathrm{~T}_{1}+{ }^{3} \mathrm{O}_{2} \rightarrow \mathrm{S}_{0}+{ }^{1} \mathrm{O}_{2}
\end{aligned}
$$

where $S_{0}, S_{1}$ and $T_{1}$ are the ground singlet, first excited singlet and first excited triplet states of the photosensitiser, respectively and ${ }^{3} \mathrm{O}_{2}$ and ${ }^{1} \mathrm{O}_{2}$ are the ground triplet and first excited singlet states of molecular oxygen, respectively. Once generated, ${ }^{1} \mathrm{O}_{2}$ may undergo radiative decay at $1270 \mathrm{~nm}$ with a low probability. This luminescence is routinely measurable in solution (Krasnovsky, 1998), but in vitro and in vivo the lifetime of ${ }^{1} \mathrm{O}_{2}$ drops dramatically, from approximately $3 \mu \mathrm{s}$ to around $100 \mathrm{~ns}$ (Moan and Berg, 1991; Schweitzer and Schmidt, 2003) because of the rapid reaction of ${ }^{1} \mathrm{O}_{2}$ with surrounding biomolecules. Likewise, the probability of radiative decay drops, such that measurement of this luminescence in biological media has traditionally not been feasible due to limited detector sensitivity and/or temporal response. Nevertheless, there has been significant interest in doing this, both for basic photobiological research and as a potential PDT dosimetry tool (Parker, 1987; Gorman and Rodgers, 1992).

In 2002, we showed for the first time that this is now possible using a novel near-infrared (NIR)-sensitive photomultiplier tube (PMT) (Niedre et al, 2002b). Specifically, we measured ${ }^{1} \mathrm{O}_{2}$ 
luminescence in vitro from leukaemia cells and in vivo in normal liver and skin of Wistar rats, sensitised with aluminium tetrasulphonated phthalocyanine $\left(\mathrm{AlS}_{4} \mathrm{Pc}\right)$. Subsequently, Hirano et al (2002) also showed that this was possible in vivo in implanted murine tumours sensitised with ATX-S10 using the same PMT.

More recently, we published a set of experiments that showed that ${ }^{1} \mathrm{O}_{2}$ luminescence was a useful PDT dose metric in vitro (Niedre et al, 2002a, 2003). Specifically, this demonstrated that the killing of OCI-AML5 leukaemia cells treated with aminolevulinic acid (ALA)-induced protoporphyrin IX (PpIX) PDT correlated very strongly with the ${ }^{1} \mathrm{O}_{2}$ luminescence measured during treatment, regardless of initial photosensitiser concentration, irradiance or molecular oxygen concentration. These experiments differed from our initial feasibility study in that the light and photosensitiser conditions were typical of clinical PDT treatments (as opposed to being optimised for generation of ${ }^{1} \mathrm{O}_{2}$ ) and, hence, substantial technical upgrades were required to the detection system.

Following this encouraging first step, we report here a set of experiments that extend this concept to an in vivo model, specifically the normal skin of hairless mice sensitised with ALAPpIX. For this, we used an available green $(523 \mathrm{~nm})$ light source, for which the ${ }^{1} \mathrm{O}_{2}$ generation and PDT effect were both confined to relatively superficial tissue. This model is based on studies conducted by Robinson et al (1998) that attempted to correlate PpIX photobleaching with the observed skin response measured daily for 2 weeks following treatment. Here, we observed (as did Robinson et al) a strong irradiance dependence of the response, despite identical ALA concentrations and total treatment fluence. We show that the ${ }^{1} \mathrm{O}_{2}$ luminescence generated during treatment correlates well with the observed skin response in all cases, regardless of the treatment fluence or irradiance. To our knowledge, this is the first time that such a correlation has been demonstrated in vivo.

As will be discussed, these data support the hypothesis that ${ }^{1} \mathrm{O}_{2}$ is the primary ROS involved in PDT in vivo. They are also encouraging for the development of ${ }^{1} \mathrm{O}_{2}$ luminescence-based preclinical and/or clinical PDT dosimetry systems.

\section{MATERIALS AND METHODS}

\section{Theory}

As described in detail previously (Niedre et al, 2002b), the local ${ }^{1} \mathrm{O}_{2}$ concentration as a function of time generated by a short laser pulse is given by:

$$
\left[{ }^{1} \mathrm{O}_{2}\right](t)=N \sigma\left[\mathrm{S}_{0}\right] \Phi_{\mathrm{D}} \frac{\tau_{\mathrm{D}}}{\tau_{\mathrm{T}}-\tau_{\mathrm{D}}}\left[\exp \left(-t / \tau_{\mathrm{T}}\right)-\exp \left(-t / \tau_{\mathrm{D}}\right)\right]
$$

where $N$ is the number of photons per $\mathrm{cm}^{2}$ in the excitation pulse incident on the sample, $\sigma$ is the photosensitiser ground state absorption cross-section $\left(\mathrm{cm}^{2}\right),\left[\mathrm{S}_{0}\right]$ is the concentration of the photosensitiser ground state, $\Phi_{\mathrm{D}}$ is the quantum yield of ${ }^{1} \mathrm{O}_{2}$, and $\tau_{\mathrm{T}}$ and $\tau_{\mathrm{D}}$ are the photosensitiser triplet-state lifetime and ${ }^{1} \mathrm{O}_{2}$ lifetime, respectively.

The total number of photons emitted in the radiative decay of ${ }^{1} \mathrm{O}_{2}$ at $1270 \mathrm{~nm}$ is given by

$$
L_{1270}(t)=\frac{\left[{ }^{1} \mathrm{O}_{2}\right](t)}{\tau_{\mathrm{R}}}
$$

where $\tau_{\mathrm{R}}$ is the radiative lifetime of ${ }^{1} \mathrm{O}_{2}$ in the specific environment. Equation (C) can be integrated over time to give the total number of photons emitted after excitation by a single laser pulse as

$$
\int L_{1270}(t) \mathrm{d} t=\frac{N \sigma\left[\mathrm{S}_{0}\right] \Phi_{\mathrm{D}} \tau_{\mathrm{D}}}{\tau_{\mathrm{R}}}
$$

Hence, the concentration of ${ }^{1} \mathrm{O}_{2}$ generated in a sample is directly proportional to the total emitted luminescence.
We approximate integral (D) experimentally by counting the total luminescence in the interval between 2 and $90 \mu$ s following the laser pulse and subtracting background contributions. Since the laser was operating at $10 \mathrm{kHz}$, by counting in this interval the system was actively measuring $88 \%$ of the time. As in our earlier work, the contributions from the first $2 \mu$ s were rejected due to strong fluorescence contributions to the signal from the photosensitiser and some optical elements. Since the kinetics of the ${ }^{1} \mathrm{O}_{2}$ luminescence were determined by Equation (B), we could expect that, despite the extremely short $\tau_{\mathrm{D}}$ in tissue, the ${ }^{1} \mathrm{O}_{2}$ full-time curve would last several $\tau_{\mathrm{T}}$. Our previous estimates for $\tau_{\mathrm{T}}$ in tissue were between 25 and $30 \mu$ s (Niedre et al, 2002b), and in the present experiments were confirmed to be 30 to $40 \mu$ s (data not shown). However, even if $\tau_{\mathrm{T}}$ was very long (e.g. due to very low $\mathrm{pO}_{2}$ ) the loss of counts would be small (i.e. $<12 \%$ ) due to the high duty cycle of the system.

\section{Apparatus}

The apparatus used to measure ${ }^{1} \mathrm{O}_{2}$ luminescence in vivo is shown in Figure 1. This system has been described in detail elsewhere (Niedre et al, 2003), with modifications made for the current experiments as follows: (i) The NIR PMT (R5509-14, Hamamatsu Corp., Bridgewater, NJ, USA) was mounted vertically, so that the detector and collection optics were above the animals. As before, the operating voltage of the PMT was set to $-1500 \mathrm{~V}$ using a high voltage power supply (model SR445, Stanford Research Systems, Sunnyvale, CA, USA); (ii) a small, $4 \mathrm{~mm} \times 4 \mathrm{~mm}$ silver-coated prism (01-PRS-411, Melles Griot Inc., Nepean, ON, Canada) was mounted directly in front of the silicon long-pass filter and used to redirect the laser beam $90^{\circ}$ towards the skin surface. This allowed illumination of the skin while maintaining close positioning between it and the detection optics and to give a high numerical aperture for maximum light collection, and (iii) the multichannel scalar was replaced with a high-speed multiscalar module (Becker and Hickl MSA-300, Boston Electronics, Brookline, MA, USA), which allowed us to operate the laser at $10 \mathrm{kHz}$ without loss of signal due to speed limitations of the electronics.

As with our earlier studies (Niedre et al, 2002a, 2003), the laser was a $523 \mathrm{~nm}$ diode-pumped, Q-switched frequency-doubled Nd:YLF (QG-523-500; Crystalaser Inc., Reno, NV, USA) with a pulse width of $\sim 10 \mathrm{~ns}$. The irradiance at the skin was controlled using a set of neutral density filters (FW2AND, Thor Labs Inc.,

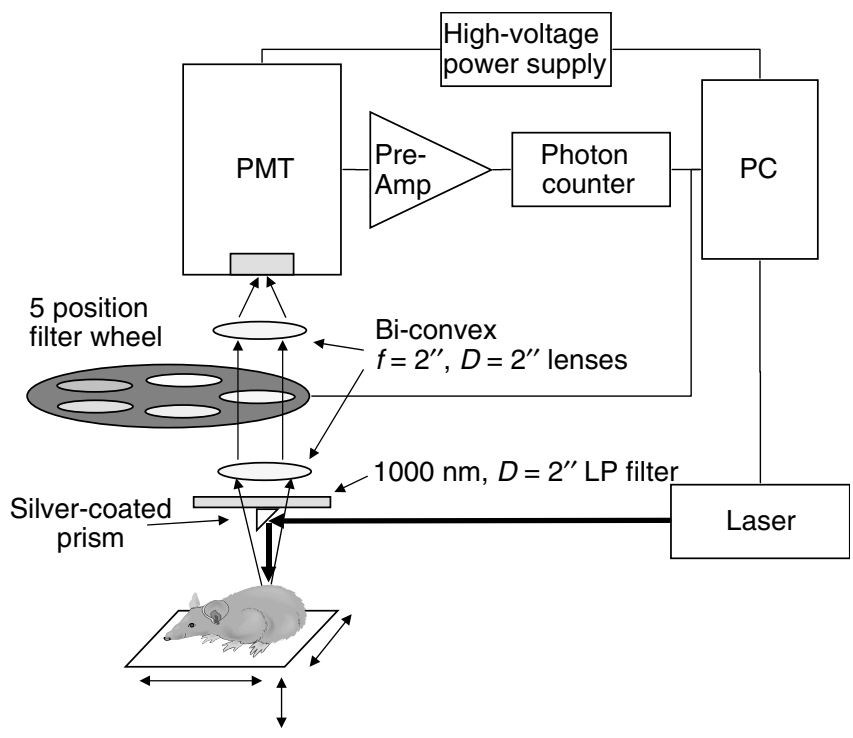

Figure I Schematic of the experimental system. 
Newton, NJ, USA). As also noted in our earlier studies (Niedre et al, $2002 \mathrm{~b}, 2003)$, there are other potential sources of luminescence in the NIR range besides ${ }^{1} \mathrm{O}_{2}$ luminescence, including detector dark counts, luminescence from optical components, tissue autofluorescence, and photosensitiser fluorescence and phosphorescence. Spectral discrimination of the detected light was, therefore, achieved using a set of five narrow-band filters centred at 1212 , 1240, 1272, 1304 and $1332 \mathrm{~nm}$ (OD3 blocking, $20 \mathrm{~nm}$ FWHM; Omega Optical, Brattleboro, VT, USA) mounted on a motorised filter wheel in front of the detector. For simplicity, these will be referred to as the 1210,1240,1270, 1300 and $1330 \mathrm{~nm}$ filters. The system was automated with a personal computer so that the filter sequence could be customised between experiments.

The mice were placed on a translatable $\mathrm{X}-\mathrm{Y}-\mathrm{Z}$ platform and the skin was kept flat with small clamping arms during treatment. A pair of small $1 \mathrm{~mW}, 635 \mathrm{~nm}$ lasers (CPS180; Thor Labs) was aligned so as to intersect at the focal point of the collection optics. This ensured that the treated spots were positioned so that the illumination/collection geometry was consistent between experiments. These lasers were shut off immediately after positioning the animal and were on for only a few seconds.

\section{Photodynamic therapy}

A total of 39 female hairless mice were used (SKH1-HR, Charles River Laboratories Inc., Wilmington, MA, USA), 7-12 weeks old. These were maintained on a low-fluorescence chow diet for at least 2 weeks prior to treatment. They were sensitised $4 \mathrm{~h}$ prior to irradiation with a distilled water solution of $20 \%$ ALA (Sigma Chemical Co., St Louis, MO, USA) with $2 \mathrm{M} \mathrm{NaOH}$ (Sigma) added to raise the $\mathrm{pH}$ to 4 and 5\% carboxymethyl cellulose (Sigma) added to increase the viscosity. This solution was applied topically to two spots (each $\sim 2 \times 2 \mathrm{~cm}^{2}$ ) on the dorsal skin and covered with a transparent adhesive dressing (Tegaderm 1626W, 3M Health Care, St Paul, MN, USA). Two PDT treatments were performed on each mouse in order to minimise the total number of animals used in the study. These treatments were chosen randomly from the set described below, so that the left side and right side generally received different treatments. Immediately before the application of ALA, the stratum corneum was stripped using medical tape to facilitate diffusion of the ALA into the epidermis.

Since we had not shown previously that it was possible to measure ${ }^{1} \mathrm{O}_{2}$ luminescence in vivo specifically with ALA-PpIX, a pilot study was conducted on a group of nine animals. The first three were sensitised with ALA-PpIX as above, and irradiated with $50 \mathrm{~mW} \mathrm{~cm}^{-2}$ treatment light, a second set of three were unsensitised controls and the final three were sensitised with ALA-PpIX and euthanised by intracardiac injection of T-61 (Houchst Roussel Vet, Whitby, SK, Canada) $5 \mathrm{~min}$ prior to irradiation. The last set allowed us to check the effect of hypoxia on the ${ }^{1} \mathrm{O}_{2}$ signal.

After this initial investigation, full treatments were performed to investigate the relationship between ${ }^{1} \mathrm{O}_{2}$ luminescence and PDT treatment response. The treatments were repeated six times in all cases and, as summarised in Table 1, were as follows: (i) a irradiance of either 15,50 or $150 \mathrm{~mW} \mathrm{~cm}^{-2}$ was delivered to a constant total fluence of $50 \mathrm{~J} \mathrm{~cm}^{-2}$; (ii) a total fluence of either 5.5 , 11 , or $22 \mathrm{~J} \mathrm{~cm}^{-2}$ was delivered at a constant irradiance of $50 \mathrm{~mW} \mathrm{~cm}^{-2}$; (iii) unsensitised control animals were irradiated with $50 \mathrm{~J} \mathrm{~cm}^{-2}$ at either 15,50 or $150 \mathrm{~mW} \mathrm{~cm}^{-2}$ and; (iv) control animals were sensitised but not irradiated. In cases (i-iii) the irradiated spot was $7 \times 7 \mathrm{~mm}^{2}$. Since the experiments were performed over a period of several months, the order in which they were performed was randomised in order to minimise any bias, for example in the system sensitivity. For practical reasons, these were not exactly the same treatments performed by Robinson et al (1998), but are all in the same range of light and drug parameters used.
Table I Summary of the PDT treatments, repeated 6 times in all cases

\begin{tabular}{|c|c|c|c|}
\hline $\begin{array}{l}\text { Fluence rate } \\
\left(\mathrm{mW} \mathrm{cm}^{-2}\right)\end{array}$ & $\begin{array}{l}\text { Fluence } \\
\left(\mathrm{J} \mathrm{cm}^{-2}\right)\end{array}$ & $\begin{array}{l}\text { Treatment } \\
\text { time (s) }\end{array}$ & $\begin{array}{c}\text { ALA } \\
\text { concentration }\end{array}$ \\
\hline $\begin{array}{l}150 \\
50 \\
15 \\
50 \\
50 \\
50 \\
15,50,150 \\
0\end{array}$ & $\begin{array}{c}50 \\
50 \\
50 \\
22 \\
11 \\
5.5 \\
50 \\
0\end{array}$ & $\begin{array}{c}333 \\
1000 \\
3333 \\
440 \\
220 \\
110 \\
333,1000,3333 \\
0\end{array}$ & \begin{tabular}{r|}
$20 \%$ \\
$20 \%$ \\
$20 \%$ \\
$20 \%$ \\
$20 \%$ \\
$20 \%$ \\
$0 \%$ \\
$20 \%$
\end{tabular} \\
\hline
\end{tabular}

Table 2 Visual skin-response scoring system (Robinson et al, 1998)

\begin{tabular}{ll}
\hline Score & Observation \\
\hline 0 & No observable effect \\
1 & Mild erythema \\
2 & Moderate erythema \\
3 & Strong erythema \\
4 & Dry desquamation \\
5 & Thin scab formation \\
6 & Thick scab formation \\
\hline
\end{tabular}

\section{Skin scoring}

Following treatment, the irradiated spot was marked and the animals were housed in darkness for $24 \mathrm{~h}$ and then observed daily for 2 weeks. On each day, an observer, blinded to the PDT treatment, assigned a numbered skin response score for each treated spot in the range $0-6$, as summarised in Table 2 . Photographs of the treated spots were taken with a calibrated colour card each day to document the response. All experiments were performed in compliance with the guidelines of the Ontario Cancer Institute Animal Care Committee.

\section{Singlet oxygen measurement and data analysis}

The detection wavelength was selected by positioning the appropriate band-pass filter in front of the PMT. In these experiments, the system was set up to acquire for 345000 laser pulses per filter. This took $37 \mathrm{~s}$, including filter wheel motion and data processing.

Near-infrared luminescence measurements were made during all of the above experiments, including unsensitised controls. All signals were corrected for minor differences in the transmission characteristics of the optics at each wavelength. For the pilot group, measurements were made at all five wavelengths, giving more spectral information. For the animals in which full treatments were given, only three wavelengths (1240, 1270 and $1300 \mathrm{~nm}$ ) were used in order to reduce the acquisition time, which totaled $111 \mathrm{~s}$.

The measured spectra in the sensitised animals were corrected for background contributions by subtracting the mean spectrum from the control animals irradiated at the same irradiance. The ${ }^{1} \mathrm{O}_{2}$ luminescence signal was then calculated as the photon counts at $1270 \mathrm{~nm}$ minus the average of the counts at 1240 and $1300 \mathrm{~nm}$ (i.e. the linearly interpolated background at $1270 \mathrm{~nm}$ ). The resulting value was then multiplied by 3 , since the system acquired at each wavelength only $1 / 3$ of the time. 


\section{RESULTS}

Figure 2 shows typical, 5 -wavelength spectra measured in the pilot group, including the sensitised, unsensitised and euthanised animals $\left(50 \mathrm{~mW} \mathrm{~cm}^{-2}\right)$. As expected for ${ }^{1} \mathrm{O}_{2}$ luminescence, a clear $1270 \mathrm{~nm}$ peak was observed for the live sensitised animals. As will be demonstrated below, significant variability was observed both in terms of ${ }^{1} \mathrm{O}_{2}$ generation and treatment response, even between animals receiving PDT under the same conditions. For this reason, representative data from a single sensitised animal are shown, as opposed to the average of the $\mathrm{O}_{2}$ luminescence observed from all of the live sensitised animals. A small but still significant peak at $1270 \mathrm{~nm}$ was observed in the unsensitised control animals, most likely due to ${ }^{1} \mathrm{O}_{2}$ generated from naturally occurring porphyrins in the skin. No peak was observed at $1270 \mathrm{~nm}$ in the sensitised but euthanised animals, confirming the oxygen dependence of the signal. Hence, the system was capable of measuring ${ }^{1} \mathrm{O}_{2}$ luminescence in this in vivo model.

Figure 3 shows the average, cumulative ${ }^{1} \mathrm{O}_{2}$ luminescence for sensitised animals treated with 15,50 and $150 \mathrm{~mW} \mathrm{~cm}^{-2}$ up to a total fluence of $50 \mathrm{~J} \mathrm{~cm}^{-2}$, after subtracting the mean control (unsensitised) spectra at the same irradiances. The total ${ }^{1} \mathrm{O}_{2}$ luminescence decreased with increasing irradiance. This trend was statistically significant between the three groups: specifically, onetailed Student's $t$-tests yielded $P=0.005$ comparing the 15 and $50 \mathrm{~mW} \mathrm{~cm}^{-2}$ treatments and $P=0.014$ between the 50 and $150 \mathrm{~mW} \mathrm{~cm}^{-2}$ treatments. Note that the error bars in Figure 3 represent the standard deviation between the six animals in each experiment. The error due to photon counting statistics was negligible compared to this systematic variability. The relevance of this observation is discussed below.

Similar curves were measured for all other treatment groups. Figure 4 summarises the mean total ${ }^{1} \mathrm{O}_{2}$ luminescence observed in each group. As would be expected, the total ${ }^{1} \mathrm{O}_{2}$ luminescence increased with radiant exposure (fluence) at a constant irradiance.

Figure 5 (inset) shows the skin scores for spots treated with $50 \mathrm{~J} \mathrm{~cm}^{-2}$ at varying irradiances, corresponding to the treatments in Figure 3, as well as the unsensitised controls at $50 \mathrm{~mW} \mathrm{~cm}^{-2}$. The unsensitised animals had no observable response to light alone at 15 or $150 \mathrm{~mW} \mathrm{~cm}^{-2}$ or to ALA alone (data not shown for

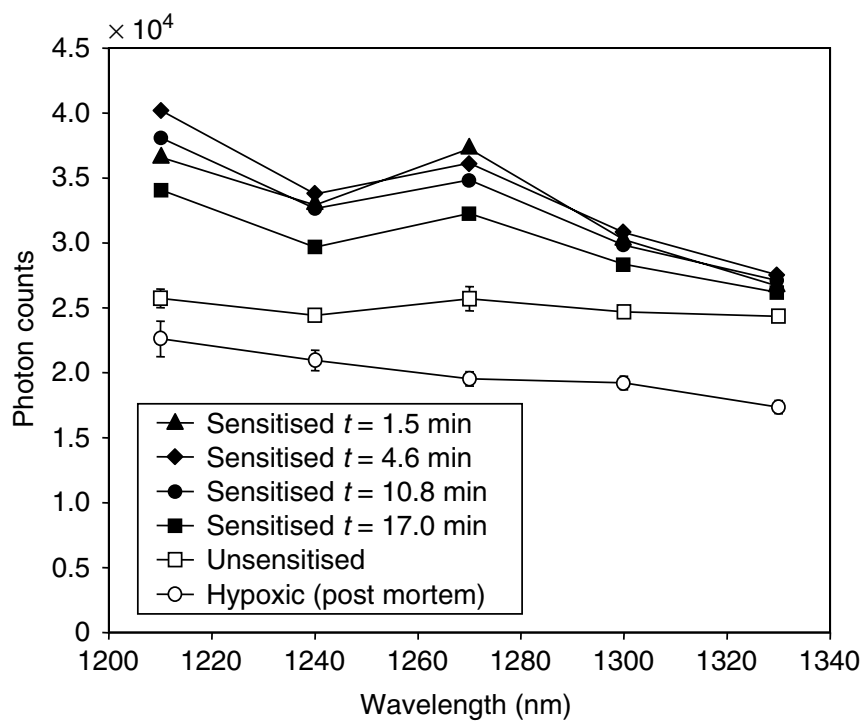

Figure 2 Typical NIR spectra measured from single sensitised, unsensitised and hypoxic animals. For the sensitised animal, the individual spectra were measured at different times during treatment. For the control and hypoxic animals, error bars reflect the standard deviation of four spectra acquired for the same animal.

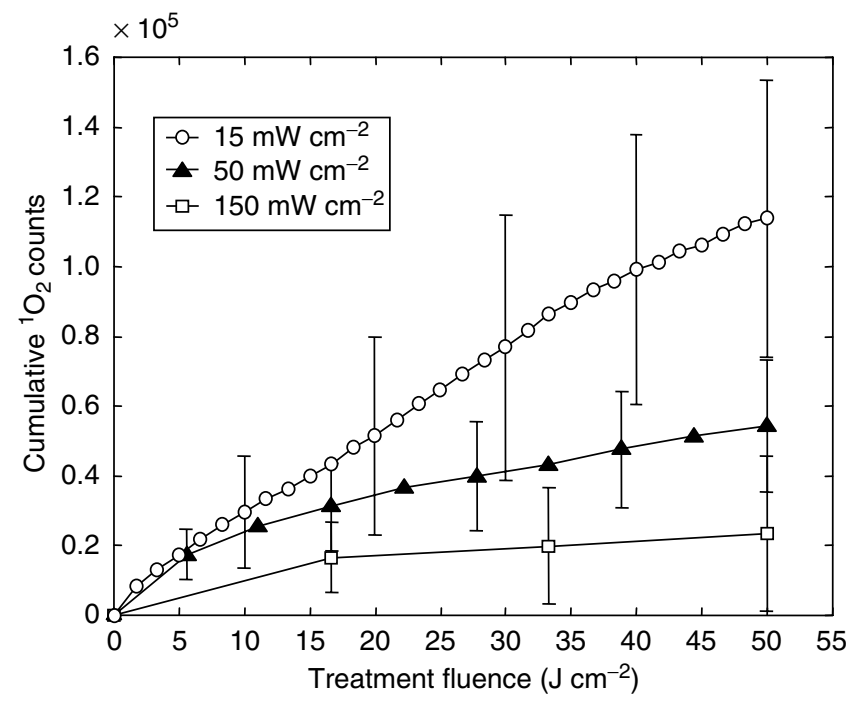

Figure 3 Cumulative ${ }^{\prime} \mathrm{O}_{2}$ luminescence in sensitised animals irradiated to $50 \mathrm{I} \mathrm{cm}^{-2}$ at 15,50 or $150 \mathrm{~mW} \mathrm{~cm}^{-2}$. Each point represents the mean for six animals, \pm Is.d. The lines are simply to guide the eye and typical error bars are shown.

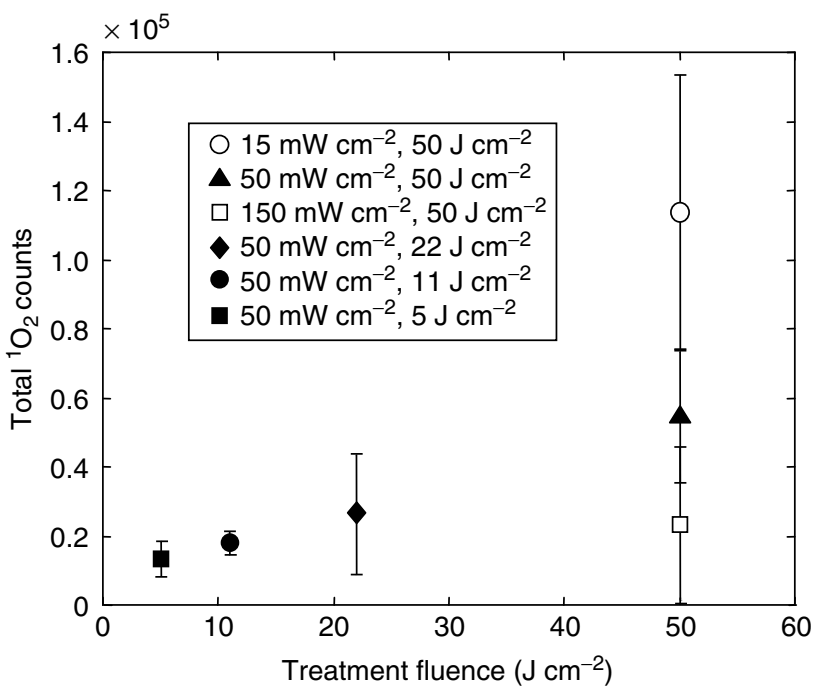

Figure 4 Total ' $\mathrm{O}_{2}$ luminescence as a function of total fluence for all treatment groups (means $\underline{ \pm}$ Is.d. in six animals).

brevity). For the sensitised animals, the skin response increased significantly with decreasing irradiance. This was statistically significant: $P=0.001$ between 15 and $50 \mathrm{~mW} \mathrm{~cm}^{-2}$ and $P=0.003$ between 50 and $150 \mathrm{~mW} \mathrm{~cm}^{-2}$. This irradiance dependence was also observed by Robinson et al (1998), and similar effects have been reported by other authors in different in vitro and in vivo models (Feins et al, 1990; Gibson et al, 1990; Foster et al, 1993; Sitnik et al, 1998), and has usually been attributed to photochemical depletion of oxygen at high irradiances. The total skin scores as a function of fluence for all treatments are summarised in Figure 5. These were defined as the sum of the 14 individual daily scores over the 2-week period in each case. Again, these are generally consistent with those obtained by Robinson et al (1998).

A striking feature in Figures 3-5 is the relatively large variability in the measurements for nominally identical PDT treatments. As will be discussed, this variability was primarily due to animal-to- 

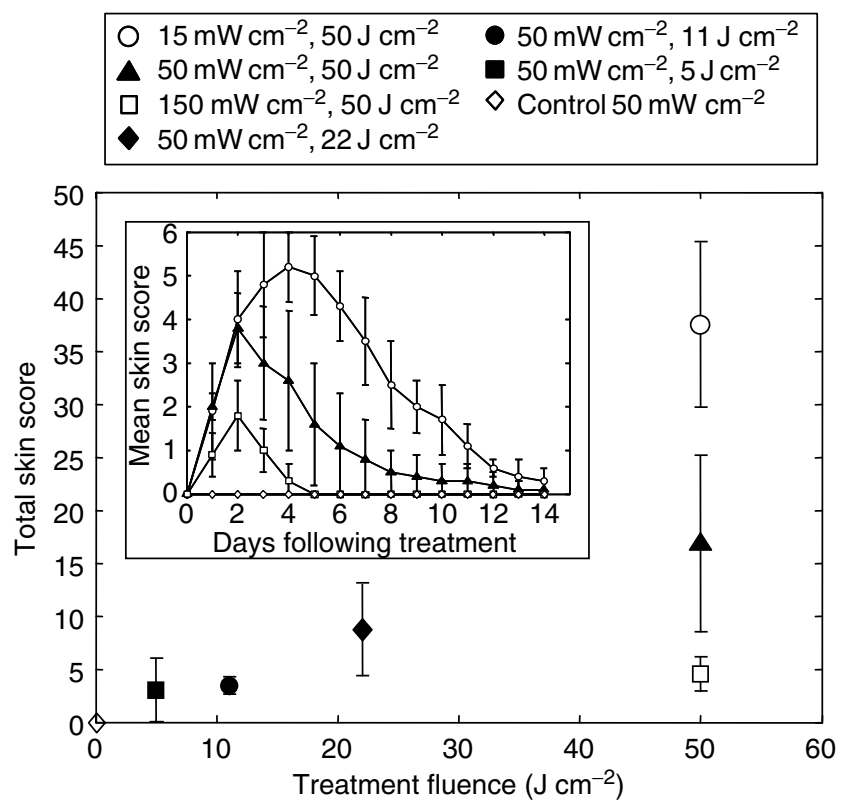

Figure 5 Total skin score (means \pm Is.d. in six animals) as a function of total fluence for all treatment conditions. Inset: skin score as a function of time following treatment in days (means \pm Is.d. in six animals).

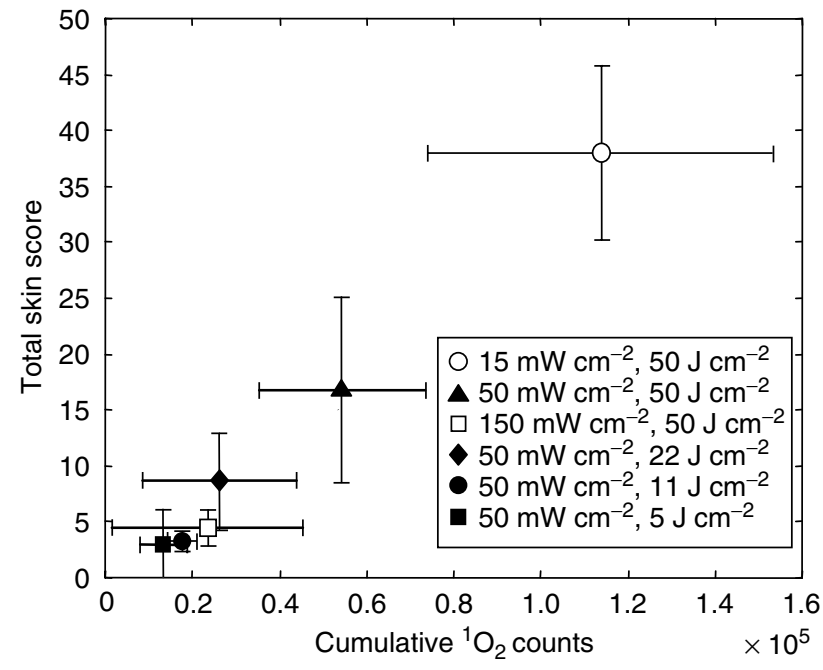

Figure 6 Total skin score (means \pm Is.d.) as a function of total ${ }^{\prime} \mathrm{O}_{2}$ luminescence (means \pm I s.d.).

animal differences in ALA uptake and/or PpIX synthesis, local skin $\mathrm{pO}_{2}$ and relative photosensitivity of the skin, as opposed to true 'experimental error'. The variability observed here was not atypically large, but serves to illustrate the difficulty inherent in predicting the outcome of PDT treatments based on administered light and photosensitiser dose alone.

The total skin score as a function of the total ${ }^{1} \mathrm{O}_{2}$ luminescence for all treatments is shown in Figure 6. There is a strong correlation with the ${ }^{1} \mathrm{O}_{2}$ luminescence, regardless of the fluence or irradiance used. Figure 7 shows the individual data points that comprise Figure 6, together with the best $\chi^{2}$ fit to a threeparameter sigmoidal curve (constrained to pass through the

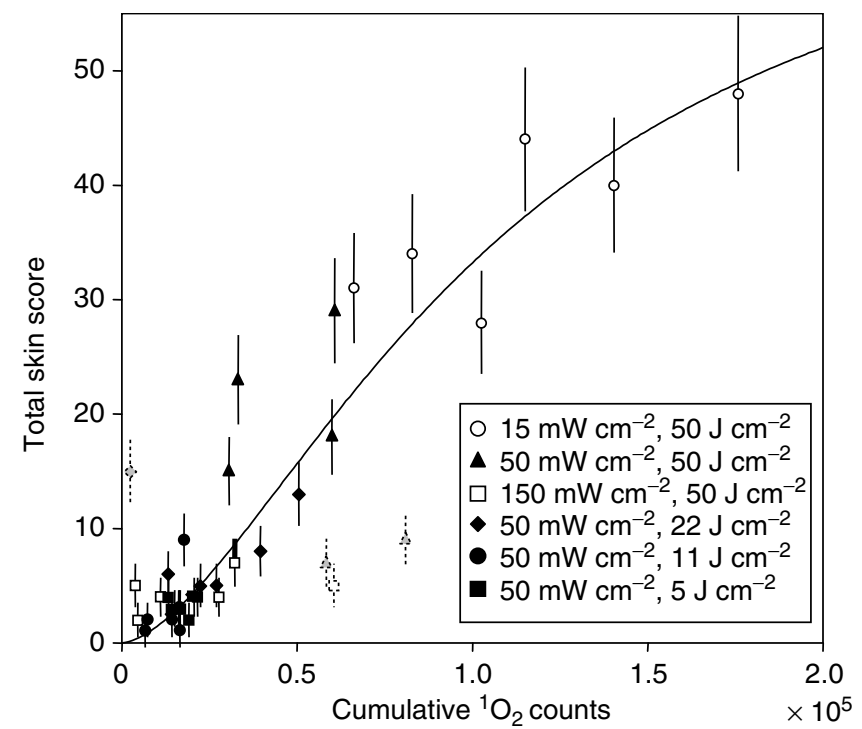

Figure 7 Total skin score as a function of total ' $\mathrm{O}_{2}$ luminescence for all individual data points that comprise the figure. The curve is the fit to Equation (E) after removal of the four outliers (open points). The error bars indicate the assumed systematic uncertainty in the visual scoring, taken as \pm 0.5 units on each score.

origin) of the form:

$$
\operatorname{TSS}(L)=\frac{A}{1+10^{-B[\log (L)-\log (C)]}}
$$

where TSS is the total skin score and $L$ is the total ${ }^{1} \mathrm{O}_{2}$ luminescence measured. The use of this functional form for the response has no a priori mechanistic basis at this time, but is a convenient way to summarise the data. This fit was performed with four outliers removed (dotted symbols in Figure 7) and this fit yielded $A=71, B=1.6$ and $C=108000$ and a reduced $\chi^{2}$ of $2.0\left(\chi^{2}\right)$ $\mathrm{NDF}=5.1$ with all data points included).

\section{DISCUSSION}

\section{Technical issues}

As with our previous work (Patterson et al, 1990; Niedre et al, 2002a, b; Niedre et al, 2003), we chose to use a set of NIR band-pass filters for spectral discrimination of the detected light rather than a monochromator (Hirano et al, 2002), since it allowed for maximum optical throughput and minimised the distance between the source and detector. Furthermore, after we verified that our system was capable of measuring ${ }^{1} \mathrm{O}_{2}$ luminescence in this in vivo model, we were able to use a set of only three filters, since the $1270 \mathrm{~nm}$ peak was unambiguous.

The addition of a small, $4 \times 4 \mathrm{~mm}$ prism in front of the collection optics allowed close positioning of the animals while allowing irradiation of the treatment spot. Since less than $1 \%$ of the field of view of the detector was blocked by this prism, the impact on signal collection was minimal.

Accurate positioning of the skin spot during ${ }^{1} \mathrm{O}_{2}$ luminescence measurements was important, since different animals were measured over an extended period of time and absolute ${ }^{1} \mathrm{O}_{2}$ luminescence measurements were compared. The pair of alignment lasers ensured that the animals were positioned reproducibly with an accuracy (height) of about $\pm 0.5 \mathrm{~mm}$ at the focal plane of the detection system, so that the complete system response was consistent. Furthermore, the laser irradiance, measured before 
each treatment was stable to $\pm 5 \%$ RMS, while the power supply for the PMT was stable to $\pm 1 \mathrm{~V}$.

\section{Singlet oxygen as an in vivo dose metric}

The key finding in this study is that treatment response in normal mouse skin in vivo correlates strongly ${ }^{1} \mathrm{O}_{2}$ luminescence measured during PDT. Furthermore, this was the case even for a range of radiant exposures and irradiances over which the response showed significant variation. In addition, as discussed earlier, significant variability was observed in both ${ }^{1} \mathrm{O}_{2}$ luminescence and skin response for nominally identical treatments. The fact that the points from the individual experiments follow a single (sigmoidal) curve (Figure 7) illustrates the ability of this technique to account for variability in treatment factors such as PpIX concentration and skin $\mathrm{pO}_{2}$. Although significantly more scatter (and outlying data points) from the parent curve is evident in Figure 7 than in our analogous in vitro studies (Niedre et al, 2003), this was not unexpected, since more variability should exist in the photobiological response between individual mice than between sets of cells from clonal populations. Also, the skin scoring system used in these experiments is somewhat subjective and may have contributed to this scatter.

The fraction of ${ }^{1} \mathrm{O}_{2}$ that undergoes radiative decay relative to all ${ }^{1} \mathrm{O}_{2}$ generated in the treatment volume (regardless of de-excitation pathway) is given by the ratio of the ${ }^{1} \mathrm{O}_{2}$ lifetime to the luminescence lifetime, that is, $\tau_{\mathrm{D}} / \tau_{\mathrm{L}}$ (Lamola, 1971). Hence, although the probability of radiative decay is extremely low in vivo (Niedre et al, 2002b), the emitted luminescence is tightly coupled to the 'active', nonradiating fraction of ${ }^{1} \mathrm{O}_{2}$. The fact that the ${ }^{1} \mathrm{O}_{2}$ luminescence measured here correlates extremely well with the treatment response further demonstrates this relationship. In addition, the ${ }^{1} \mathrm{O}_{2}$ luminescence signal was undoubtedly heterogeneous in origin in that, for example, the photosensitiser was likely concentrated in specific tissue and/or cellular compartments (e.g. mitochondrial membrane; Wilson et al, 1997b) and the oxygenation is higher in membranes than in cytosol. However, the proportion of radiative $v s$ nonradiative ${ }^{1} \mathrm{O}_{2}$ was consistent between experiments, since we used the same photosensitiser and application conditions in all cases. This might be a complicating factor if, for example, ${ }^{1} \mathrm{O}_{2}$ luminescence was compared to treatment response using different photosensitisers and administration conditions. Moreover, the effect of tissue optics in these experiments was minimal, since we deliberately chose a relatively homogeneous tissue model as opposed to, for example, a murine tumour model (Robinson et al, 1998).

This work, together along with our earlier dose-response studies in cells, supports the generally-held hypothesis that ${ }^{1} \mathrm{O}_{2}$ is the important cytotoxin involved in PDT. Furthermore, since the relationship between ${ }^{1} \mathrm{O}_{2}$ generation and treatment response holds in vivo, this work further demonstrates the utility of using ${ }^{1} \mathrm{O}_{2}$ luminescence as a PDT dosimetry tool. However, the possibility that ${ }^{1} \mathrm{O}_{2}$ is only one of the ROS generated cannot be discounted, nor can the possibility that other ROS are more important for different photosensitisers.

\section{Irradiance effects}

Strong irradiance effects were observed in these experiments, both in terms of ${ }^{1} \mathrm{O}_{2}$ luminescence generation and treatment response. Irradiance effects have been observed by other authors (Feins et al, 1990; Gibson et al, 1990; Foster et al, 1993; Robinson et al, 1998; Sitnik et al, 1998) and have usually been attributed to rapid photochemical depletion of molecular oxygen at higher irradiances. The ${ }^{1} \mathrm{O}_{2}$ luminescence measurements here appear to be consistent with this interpretation. Specifically, Figure 8 shows the cumulative ${ }^{1} \mathrm{O}_{2}$ luminescence (as in Figure 3 ) as a function of total treatment time. The fact that all of the curves appear to reach

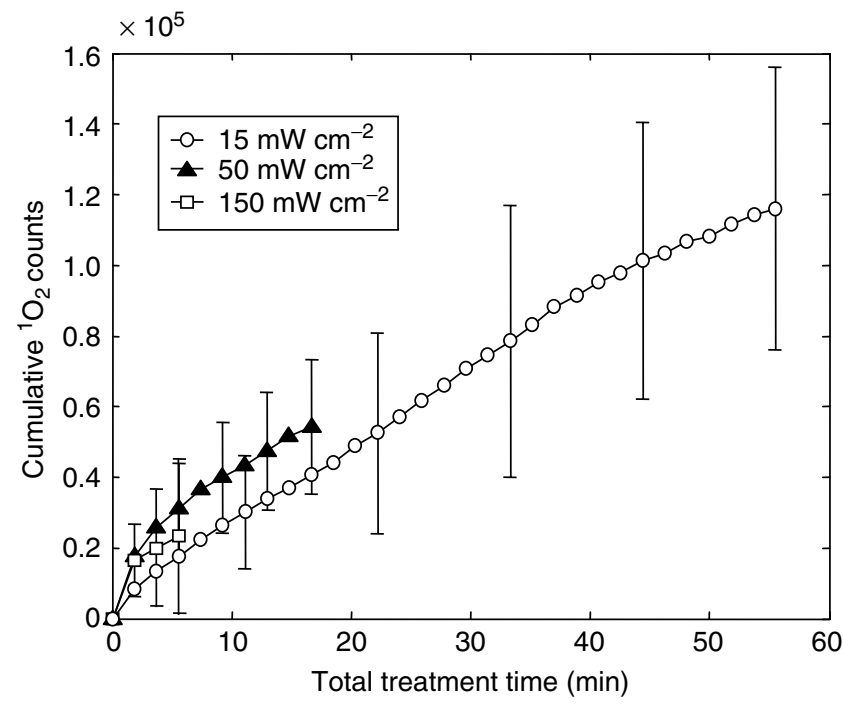

Figure 8 Total ' $\mathrm{O}_{2}$ luminescence vs total treatment time for animals that received $50 \mathrm{~J} \mathrm{~cm}^{-2}$ at 15,50 or $150 \mathrm{~mW} \mathrm{~cm}^{-2}$ (means \pm Is.d.).

approximately the same terminal slope regardless of irradiance implies that ${ }^{1} \mathrm{O}_{2}$ generation was not limited by the number of excitation photons in each laser pulse, but rather by the available molecular oxygen and/or photosensitiser ground state. We are currently investigating both of these possibilities in more detail.

\section{Other observations}

Robinson et al (1998) observed rapid photobleaching of the photosensitiser: for example, greater than $90 \%$ of the PpIX was bleached after $10 \mathrm{~J} \mathrm{~cm}^{-2}$ at their lowest irradiance. This appears to contradict our data, since the incremental ${ }^{1} \mathrm{O}_{2}$ generation at $15 \mathrm{~mW} \mathrm{~cm}^{-2}$ appeared unaffected by the bleaching of the photosensitiser and decreased only slightly at later time points (Figure 8). A possible explanation for this is the formation of photosensitive photoproducts during PpIX irradiation (Finlay et al, 2001). These photoproducts are known to absorb at $523 \mathrm{~nm}$ and therefore may have acted as secondary photosensitisers, allowing sustained photodynamic generation of ${ }^{1} \mathrm{O}_{2}$. Alternatively, it is possible that sufficient PpIX was always present during treatment, so that the concentration of molecular oxygen was the limiting factor in ${ }^{1} \mathrm{O}_{2}$ generation even after several orders of magnitude of photosensitiser photobleaching. This further illustrates the potential value of ${ }^{1} \mathrm{O}_{2}$ luminescence-based dosimetry, since complicating factors such as photobleaching, formation of photosensitive photoproducts and tissue oxygenation are all implicitly incorporated into a single measurement.

Analysis of the data of Figure 7 showed that the lowest ${ }^{1} \mathrm{O}_{2}$ luminescence counts measured from any treatment that resulted in an individual skin response score of 5 or higher (i.e. scab formation/necrosis) at any day post-treatment was 61000 photon counts. Given the system geometric collection efficiency (0.02), quantum efficiency of the detector (0.01), optical throughput of the collection optics $(0.2)$ and the probability of radiative decay of ${ }^{1} \mathrm{O}_{2}$ in tissue $\left(=\tau_{\mathrm{D}} / \tau_{\mathrm{L}} \sim 100 \mathrm{~ns} / 5.55 \mathrm{~s} \sim 2 \times 10^{-8}\right.$ ) (Niedre et al, 2002b), this was equivalent to $\sim 7 \times 10^{16}$ molecules of ${ }^{1} \mathrm{O}_{2}$ in the treatment volume. Assuming a typical cell density in tissue of around $10^{9} \mathrm{~cm}^{-3}$ and, given that the effective treatment volume was approximately $0.5 \mathrm{~cm}^{2}$ with a depth of $25 \mu \mathrm{m}$ (Robinson et al, 1998), the ${ }^{1} \mathrm{O}_{2}$ necrosis threshold for this model was about $5.8 \times 10^{10}$ molecules of ${ }^{1} \mathrm{O}_{2}$ per cell. This is can be compared to Georgakoudi et al's (1997) estimate of $\sim 7 \times 10^{9}$ molecules of ${ }^{1} \mathrm{O}_{2}$ per cell in EMT6 spheroids treated with Photofrin-PDT, and Farrel 
et al's (1991) estimate of $\sim 5 \times 10^{8}$ per cell in rat liver treated with Photofrin-PDT, Interestingly, it is also significantly higher than our own estimate of the $5.6 \times 10^{7}$ molecules ${ }^{1} \mathrm{O}_{2}$ per cell to achieve 1/e cell death in OCI-AML5 cells in vitro with ALA-PpIX (Niedre et al, 2003). This apparently higher threshold for the skin response likely reflects the relative insensitivity of normal mouse epidermal cells $v s$ leukaemia cells, and the lack of a vascular component in the treatment response to ALA-PpIX PDT $v s$ that of PhotofrinPDT. It should also be noted that this result is sensitive to the assumed treatment depth; here, we have assumed that PpIX synthesis is confined to the epidermis as described by Kennedy and Pottier (1992) and Robinson et al (1998), but there may have been contributions from the dermis as well. This would lead to the above threshold value being overestimated.

\section{CONCLUSIONS}

In summary, this work demonstrates the potential value of ${ }^{1} \mathrm{O}_{2}$ luminescence as a dose metric in vivo. Combined with our previous studies, the prospect of further extending this work towards a clinical dosimetry system is encouraging. We plan to repeat these studies next in an implanted tumour model that has an increased level of complexity due to inherent heterogeneity in optical properties, photosensitiser uptake and oxygenation. This may require further modification of the system to provide spatial information as well as single, volume-averaged ${ }^{1} \mathrm{O}_{2}$ luminescence measurements. If successful, we then plan to perform a clinical demonstration of ${ }^{1} \mathrm{O}_{2}$ luminescence measurements during PDT, probably initially on skin cancer patients.

\section{ACKNOWLEDGEMENTS}

This work was supported by the Canadian Cancer Society under a grant from the National Cancer Institute of Canada. We also thank Hamamatsu Corp., Hamamatsu City, Japan, and in particular Dr Ken Kaufmann (Hamamatsu, Bridgewater, NJ, USA), for supporting the acquisition of the PMT system, and the Canadian Foundation for Innovation and the Princess Margaret Hospital Foundation for equipment support. The assistance of Anoja Giles, Sandra Lafranc, and Dr Kai Zhang is also gratefully acknowledged. Dr Tom Foster provided invaluable advice on the interpretation of the above results, for which we are most grateful.

\section{REFERENCES}

Dougherty TJ, Gomer CJ, Henderson BW, Jori G, Kessel D, Korbelik M, Moan J, Peng Q (1998) Review: photodynamic therapy. J Natl Cancer Inst 90: $889-905$

Dysart JS, Patterson MS, Farrell TJ, Singh G (2002) Relationship between mTHPC fluorescence photobleaching and cell viability during in vitro photodynamic treatment of DP16 cells. Photochem Photobiol 75: $289-295$

Farrel TJ, Wilson BC, Patterson MS, Chow R (1991) The dependence of photodynamic threshold dose on treatment parameters in normal rat liver in vivo. Proc SPIE 1426: $146-155$

Feins RH, Hilf R, Ross H, Gibson SL (1990) Photodynamic therapy for human malignant mesothelioma in the nude mouse. J Surg Res 49: $311-314$

Finlay JC, Conover DL, Hull EL, Foster TH (2001) Porphyrin bleaching and PDT-induced spectral changes are irradiance dependent in ALAsensitized normal rat skin in vivo. Photochem Photobiol 73: 53-63

Foster TH, Hartley DF, Nichols MG, Hilf R (1993) Fluence rate effects in photodynamic therapy of multicell tumor spheroids. Cancer Res 53: $1249-1254$

Georgakoudi I, Nichols MG, Foster TH (1997) The mechanism of photofrin photobleaching and its consequences for photodynamic dosimetry. Photochem Photobiol 65: 135-144

Gibson SL, VanDerMeid KR, Murant RS, Raubertas RF, Hilf R (1990) Effects of various photoradiation regimens on the antitumor efficacy of photodynamic therapy for R3230AC mammary carcinomas. Cancer Res 50: $7236-7241$

Gorman AA, Rodgers MAJ (1992) Current perspectives of singlet oxygen detection in biological environments. J Photochem Photobiol B 14: $159-176$

Hirano T, Kohno E, Nishiwaki M (2002) Detection of near infrared emission from singlet oxygen in PDT with an experimental tumor bearing mouse. J Jpn Soc Laser Surg Med 22: 99-108, (in Japanese)

Kennedy JC, Pottier RH (1992) Endogenous protoporphyrin IX, a clinically useful photosensitizer for photodynamic therapy. J Photochem Photobiol B 14: 275 - 292

Krasnovsky AA (1998) Singlet molecular oxygen in photobiochemical systems: IR luminescence studies. Membrane Cell Biol 12: $665-690$

Lamola AA (1971) Creation and Detection of the Excited State. New York: Marcel Dekker Inc

Moan J, Berg K (1991) The photodegradation of porphyrins in cell can be used to estimate the lifetime of singlet oxygen. Photochem Photobiol 53: $549-553$

Niedre MJ, Patterson MS, Boruvka N, Wilson BC (2002a) Measurement of singlet oxygen luminescence from AML5 cells sensitized with ALAinduced PpIX in suspension during photodynamic therapy and correlation with cell viability after treatment. Proc SPIE 4612: $93-101$

Niedre M, Patterson MS, Wilson BC (2002b) Direct near-infrared luminescence detection of singlet oxygen generated by photodynamic therapy in cells in vitro and tissues in vivo. Photochem Photobiol 75: 382-391

Niedre MJ, Secord AJ, Patterson MS, Wilson BC (2003) In vitro tests of the validity of singlet oxygen luminescence measurements as a dose metric in photodynamic therapy. Cancer Res 63: 7986-7994

Parker JG (1987) Optical monitoring of singlet oxygen during photodynamic treatment of tumors. IEEE Circ Devices Mag 3: 10-21

Patterson MS, Madsen SJ, Wilson BC (1990) Experimental tests of singlet oxygen luminescence monitoring in vivo during photodynamic therapy. J Photochem Photobiol B 5: 69-84

Robinson DJ, de Bruijn HS, van der Veen N, Stringer MR, Brown SB, Star WM (1998) Fluorescence photobleaching of ALA-induced protoporphyrin IX during photodynamic therapy of normal hairless mouse skin: the effect of light dose and irradiance and the resulting biological effect. Photochem Photobiol 67: 140-149

Schweitzer C, Schmidt R (2003) Physical mechanisms of generation and deactivation of singlet oxygen. Chem Rev 103: 1685-1757

Sitnik TM, Hampton JA, Henderson BW (1998) Reduction of tumor oxygenation before and after photodynamic therapy in vivo: effects of fluence rate. Br J Cancer 77: 1386-1394

Stewart F, Baas P, Star W (1998) What does photodynamic therapy have to offer radiation oncologists (or their cancer patients)? Radiother Oncol 48: $233-248$

Weishaupt KR, Gomer CJ, Dougherty TJ (1976) Identification of singlet oxygen as the cytotoxic agent in photo-inactivation of a murine tumor. Cancer Res 36: 2326-2392

Wilson BC, Olivo M, Singh G (1997b) Subcellular localization of Photofrin and aminolevulinic acid and photodynamic cross-resistance in vitro in radiation-induced fibrosarcoma cells sensitive or resistant to Photofrinmediated photodynamic therapy. Photochem Photobiol 65: 166-176

Wilson BC, Patterson MS, Lilge L (1997a) Implicit and explicit dosimetry in photodynamic therapy: a new paradigm. Lasers Med Sci 12: 182-199 